\title{
College Education and Social Trust: An Evidence-Based Study on the Causal Mechanisms
}

\author{
Jian Huang • Henriëtte Maassen van den Brink • Wim Groot
}

Accepted: 17 October 2010/Published online: 28 October 2010

(C) The Author(s) 2010. This article is published with open access at Springerlink.com

\begin{abstract}
This paper examines the influence of college education on social trust at the individual level. Based on the literature of trust and social trust, we hypothesize that life experience/development since adulthood and perceptions of cultural/social structures are two primary channels in the causal linkage between college education and social trust. In the first part of the empirical study econometric techniques are employed to tackle the omittedvariable problem and substantial evidence is found to confirm the positive effect of college education. In the second part contemporary information is used to examine the hypothetical mechanisms in the causal inference. That life experience is a primary channel via which college education promotes social trust fails to find support in our examination, while individual perceptions of cultural and social structures explain up to $77 \%$ of the causal effect.
\end{abstract}

Keywords Social trust $\cdot$ College education

\section{Backgrounds}

Trust refers to a variety of phenomena that enable individuals to accept risks in dealing with others, solve collective action problems, or act in ways that seem contrary to standard

\section{J. Huang}

Top Institute Evidence Based Education Research, Department of General Economics (TIER), University of Amsterdam, Room 3.67, Building E, Roetersstraat 11, 1018 WB Amsterdam, The Netherlands e-mail: j.huang@uva.nl

H. M. van den Brink

Top Institute Evidence Based Education Research, Department of General Economics (TIER), University of Amsterdam, Room 11.05, Building E, Roetersstraat 11, 1018 WB Amsterdam, The Netherlands

e-mail: h.maassenvandenbrink@uva.nl

W. Groot $(\bowtie)$

TIER Top Institute Evidence Based Education Research, Department of Health, Medicine and Life Sciences, Maastricht University, P.O. Box 616, 6200 MD Maastricht, The Netherlands e-mail:w.groot@beoz.unimaas.nl 
definitions of self-interest (Levi 1998, p. 78). According to Gambetta (1988, p. 217), "trust is a particular level of the subjective probability with which an agent assesses that another agent or group of agents will perform a particular action, both before he can monitor such an action (or independently of his capacity ever to be able to monitor it) and in a context in which it affects his own action". Misztal (1996, p. 9) suggests "to trust is to believe that the results of somebody's intended action will be appropriate from our point of view". In line with the notion of trust discussed by Gambetta (1988, p. 78), Misztal (1996, p. 217), Hardin (1998, p. 12), Warren (1999, p. 311), and Delhey and Newton (2005), we offer a working definition of trust as the perceived likelihood by which an individual expects that another individual or group, at worst, will not knowingly or willingly do you harm, and at best, will act in your interests.

The focus of this paper is on trust in generalized others, which is known as social trust or generalized trust in the literature. Social trust denotes impersonal trust between random people and it differs fundamentally from personal trust by being extended to people on whom the trusting part has no direct information (Hardin 2003, p. 13; Delhey and Newton 2005; Paxton 2007).

Measurement of social trust is generally based on a standard survey question: "Generally speaking, would you say that most people can be trusted or that you can't be too careful in dealing with people?" This operationalisation of social trust has been widely used for more than four decades in empirical studies and surveys around the world. Empirical studies on the benefits of social trust employ this measurement as the main indicator. These studies provide a plethora of evidence for the positive effects of social trust at the individual and societal level (see, e.g. Putnam 1993, pp. 167-71; Kollock 1994; Fukuyama 1995, pp. 23-32; La Porta et al. 1997; Knack and Keefer 1997; and Zack and Knack 2001).

Despite a large volume of literature on the social trust theory and the social trust benefits, limited efforts have been given to the empirical exploration of the formation of individual social trust from a development perspective. ${ }^{1}$ In particular, it has been commonly agreed that education is a crucial determinant of social trust. The exact magnitude of the education effect is, however, an under-studied topic. Education is generally considered as an exogenous independent variable in the equation of social trust. Few empirical studies have attempted to isolate the causal effect of education from the influences of confounding variables. Insofar little empirical evidence has been found to clarify a causal linkage between education and social trust. The theoretical rationales on the role of education remain hypothetical and untested.

In this paper we explore the role of college education in the formation of individual social trust, using the rich data of a British cohort from the National Child Development Study (NCDS). We begin with a theoretical review on the micro aspects of social trust, considering that risks are an essential element and emphasizing life experience/development and perceptions of cultural/social structures as two primary sources of expectations and beliefs for each individual in society. Based on the theoretical insights, we hypothesize two channels in the causal pathway between college education and social trust: heterogeneities in life experience/development attributable to education difference and heterogeneities in perceptions of cultural/social structures attributable to education difference.

\footnotetext{
1 The majority of empirical studies are focused on exploring the sources of social trust at the national or community level. Existing empirical studies of social trust at the individual level generally rely on contemporary information to examine the variation in individual trust on generalized others-income, economic class, community characteristics, and life satisfaction (e.g. Brehm and Rahn 1997; Glaeser et al. 1999; Alesina and La Ferrara 2000, 2002). Few empirical works have been done to elucidate the influences of early-life factors on the development of social trust in the life course.
} 
Our empirical study proceeds in two steps. In the first step we employ econometric techniques to isolate the influence of confounding variables and quantify the causal effect (in terms of average treatment effect) of college education. Strong econometric evidence is found to support the positive role of college education in the formation of social trust. The level of social trust of college graduates exceeds that of non-college graduates by $7.5 \%$ point. This implies that a college education increases the probability of trusting generalized others by about $16 \%$ of its standard deviation.

In the second step we introduce contemporary information of individual life experience/ development and contemporary information of individual perceptions of cultural/social structures to examine the theoretical insights on the role of college education. The hypothesis that college education promotes social trust via its power to shape later-life development fails to find support in the empirical analysis, while individual perceptions of cultural/social structures explain up to $77 \%$ of the effect of college education on social trust. We confirm that individual understanding of cultural/social structures is the primary channel in the causal pathway from college education to social trust.

The remainder of this paper is divided into four sections. Section 2 gives a theoretical review of the micro aspects of social trust and hypothesizes two channels in the causal linkage between college education and social trust. This section also presents a succinct illustration of the econometric techniques that are employed in our empirical examinations. The third section presents an introduction of the NCDS dataset and an illustration of an instrumental variable approach. The fourth section provides an evaluation of the causal effect of college education and offers tests on the validity of the hypotheses on the causal effect of college education. The fifth section offers concluding remarks.

\section{Theory, Hypotheses and Evaluation Techniques}

Trust is not one thing and does not have one source. It has a variety of forms and causes (Levi 1998, p. 79). A person's trust in generalized others, likewise, has different aspects and they do not form a single syndrome (Newton 2001). As a result, some researchers argue that the standard survey question of social trust is not clear to respondents about whom to trust or under which circumstances. The ambiguity in the measurement of social trust could make it difficult for researchers to explore respondents' perceptions of the context relating to the survey question. In order to perform a comprehensive study of the role of college education in the development of social trust, we take efforts to present a theoretical review of the micro aspects of social trust. Based on the theoretical insights, we establish two hypothetical mechanisms to explain the causal influence of college education, which we will examine in the empirical analysis.

\subsection{Social Trust Theory from a Micro Perspective}

Social trust reflects "a belief in the benevolence of human nature in general" (Yamagishi and Yamagishi 1994) and it implies risks to the truster of being dependent on the characteristics (competence and motives) of the trusted in social interactions (Lewis and Weigert 1985; Bluhm 1987; Coleman 1990, p. 91; Levi 1998, p. 79; Hardin 2003, p. 19). Coleman (1990, p. 91) identifies risk as an essential element in the definition of trust. Levi (1998, p. 79) proposes that the actual extent of risk and the extent to which the truster is taking a "sensible" risk are variables, and they are partially functions of the trustworthiness of not only the 
trustee but also those on whom the truster relies for information and sanctions against a trustbreaker.

As expectations and beliefs are characterized by risks, social trust at the individual level involves an assessment of the trustworthiness of generalized others in which a truster makes an estimate of the competence (or reliability) and an estimate of the feeling of moral obligation (or goodwill) of the "average person" to carry out the fiduciary duties and responsibilities (Barber 1983, pp. 9-10). According to a large amount of trust and social trust literature (e.g. Hardin 1996; Sztompka 1999, pp. 65-68; Rothstein and Stolle 2002; Knight 2003, p. 358; Paxton 2007), there are two primary sources of expectations and beliefs for each individual in a society: an individual's previous experience (or individual characteristics) and cultural and social structures (or contextual characteristics).

Firstly, personal life experience is an important aspect in an individual's assessment of the trustworthiness of generalized others (Brehm and Rahn 1997; offe 1999; Hardin 1996; Alesina and La Ferrara 2000, 2002; Uslaner 2002; Paxton 2007). Social trust at the individual level is subject to first-hand experience of the social world and the people in itfriends, family, neighbors, colleagues, and daily contacts with others, which enable a truster to make a judgment about the trustworthiness of generalized others.

People who have matured in a disadvantaged position are more inclined to have a lower sense of the reliability or goodwill of others (Paxton 2007), because they were more likely to have the experience of being exposed to the "darker side" of society. Being victim of a crime, for example, contributes to more distrusting views (Ferraro 1995). As a prudent measure against the risk of negative social encounters or being exploited, these people are less likely to trust others with whom they do not have direct contact. People who have grown up in a well-to-do environment, on the contrary, have a higher belief in the benevolence of human nature in general. They are generally happier with how the life is going and more likely to give affirmative responses in trust surveys (Brehm and Rahn 1997; Uslaner 2002, p. 33).

Socializing activities are an important source of human information practices (Granovetter 1973). Establishing and maintaining good social relationships facilitate access to relevant information in detecting and assessing risks in an uncertain environment. Lack of socialization may prevent a person from developing communication skills and lead to misunderstanding and distrusting of others. Significant experiences in social interactions, especially traumatic experience, throughout the life course may influence the assessments of the trustworthiness of others (Boyle and Bonacich 1970; Hardin 1996). Experience of divorce, for instance, could reduce an individual's assessment of the goodwill of others, thereby generally lowering his or her view of the trustworthiness of people in general (Alesina and La Ferrara 2000, 2002; Rahn et al. 2003; Paxton 2007).

Secondly, characteristics of cultural and social structures are also an important aspect in the assessment of the trustworthiness of generalized others (Zack and Knack 2001; Rothstein and Stolle 2002; Knight 2003, pp. 358-71; Paxton 2007). These cultural and social structures include norms and conventions, as well as formal/institutional arrangements in society,

Social norms and conventions are the informal rules that configure social life. They create an incentive structure that can place pressure on an individual to honor trust (Yamagishi and Yamagishi 1994; Buskens 2002; Knight 2003). These informal rules instantiate commonly-held behavior of others and dictate differential behavior across social groups. The more a society or community shares a common set of moral values, the greater the likelihood that a high level of collective trust will arise (Fukuyama 1995, p. 153). Knight (2003, pp. 358-71) and Hardin (2003, pp. 16-17) suggest that the 
trustworthiness created by norm compliance can lead to generalized trust in the community. Rapid social change that undermines the normative order is likely to produce an increase in distrust and untrustworthy behavior (Sztompka 1999, pp. 151-90; Delhey and Newton 2005).

Social heterogeneities are considered to have an adverse influence on the emergence and maintenance of social trust (Lukes 1991; Putnam 2000, p. 400; Alesina and La Ferrara 2000, 2002; Marshall and Stolle 2004; Welch et al. 2005). Heterogeneities in the identity of social norms and conventions may undermine the general beliefs about the willingness of others to cooperate (Knight 2003). The greater the asymmetry of interests reflected in social norms and conventions, the higher the distrust between members of different social, racial or ethnic groups.

Individuals also resort to formal structural arrangements, such as legal system and public institutions to complement and increase the effectiveness of informal constraints in a socially diverse environment (North 1990, pp. 46-47). Formal structural arrangements provide the truster assurance against potential risks involved in trusting others with whom there is no personal knowledge, by the (partial) presence of agencies in monitoring the conduct of the trustee, providing conduct information, and sanctioning law-breaker (Levi 1998, p. 84).

The characteristics of institutional arrangements, such as efficiency, credibility, impartiality and fairness, are influential in generating and maintaining social trust (Rothstein and Stolle 2002). In a society where legal system and public institutions enforce trustworthiness in a fair and effective manner, people perceive fewer risks of being exploited or taken advantage of in social interactions and they will therefore believe that "most people can be trusted". As Lewis and Weigert (1985) declare, trust exists in a social system when individuals are secure in their expectations.

Some research has found the distribution of resources, in particular, economic resources, to be an important determinant of social trust (Alesina and La Ferrara 2000, 2002; Zack and Knack 2001; Delhey and Newton 2005). Obtainable resources serve as a kind of insurance for the risks involved in trusting others. In a society where substantial inequality exists in the distribution of resources, it is less likely for the disadvantaged group to draw positive inference about the attitudes of resource-favored groups and to cooperate with members of the dominant group (Knight 2003, pp. 358-60). People from disadvantaged group may have higher suspicion of the competence and willingness of institutional arrangements to act in the interest of the disadvantaged or treat them impartially and fairly. Consequently, the functions of institutional arrangements are weakened as reliable assurance against potential risks involved in social interactions.

Zack and Knack (2001) show that cultural and social structures are the most important determinants of social trust at the national level. In their study, the social environment (similarity or differences in social norms and conventions), the economic environment (income and the income distribution), and the legal environment (institutions that enforce contracts) account for $76 \%$ of the variation in trust levels across countries.

It is persons who can trust or be trusting (Levi 1998, p. 79). An individual's assessment of the trustworthiness of generalized others is subject to this person's understanding of the content of social norms and conventions, and perceptions of the competence and willingness of institutional arrangements in the enforcement of trustworthiness.

Understanding the contents of social norms and conventions is the key to understanding their effects in rewarding compliance behavior and punishing noncompliance, which is fundamental in predicting the behavior of others. Individuals with limited knowledge of social norms and conventions are less likely to trust others within heterogeneous groups, 
especially in a socially diverse or a rapidly changing environment. People who are generally pessimistic about (reaching a societal or between-group consensus in) the existing normative values may have a higher preference for powerful institutional arrangements, such as strict government censorship and stiff penalties, as substitute of the informal constraints in the enforcement of trustworthiness.

Social trust is sustained by people's confidence in the competence and commitment of formal structural arrangements in protecting the interest of generalized people (Brehm and Rahn 1997; Levi 1998, p. 81; Rothstein and Stolle 2002). In assessing whether "most people can be trusted", one may also make an estimate of the trustworthiness of political and legal institutions. An individual who believes these institutions are effective, credible and unbiased agencies (in monitoring and enforcing trustworthy conduct) has probably a lower perceived likelihood of being exploited or taken advantage of in social interactions, and this individual is therefore more likely to express that "most people can be trusted" in the survey. An individual's attitude toward institutional arrangements entails the perceived performance and motives of institutional arrangements in the distribution of resources. One may be more suspicious of the competence and impartiality of institutional arrangements in the enforcement of trustworthiness, when this person feels that institutional arrangements perform insufficiently in the distribution of wealth.

\subsection{College Education and the Formation of Individual Social Trust}

It has been commonly agreed in economic and social literature that education is a crucial determinant of social trust at the individual level. Highly-educated people are more likely to do well economically. The advantages in economic and social resources may bring highly-educated people more confidence in handling the risks involved in trusting generalized others. Knack and Keefer (1997) and Knack and Zak (2002) argue that trust is created in the education system by making individuals better informed and better at interpreting perceived information, as well as making them more conscious of the consequences of actions taken by themselves and others. Moreover, schooling might have an important socialization effect that may give young people a more positive attitude towards people in general (Bjørnskov, 2007). Yamagish (2003), p. 130) suggests that higher education makes students of elite college high trusters. According to Helliwell and Putnam (1999), higher average education levels may help to create a climate of trust that is selfreinforcing in which highly-educated people are in turn more likely to trust others.

In empirical studies, education is considered as an essential factor in the social trust equation. The estimated education effects vary across studies due to heterogeneities in survey sources and methodological or contextual variations. Huang et al. (2009) conducted a meta-analysis on the estimates of the education effects from empirical studies which have included education achievement as an independent variable and reported statistical data (t-statistics, p-value or standard error). In the meta-analysis, we synthesized 154 estimates of the education effects on social trust from 28 empirical studies and we found out that, overall, one additional year of schooling increases individual social trust by $4.6 \%$ of its standard deviation.

The correlation statistics or simple regression statistics in the existing studies do not, however, necessarily reflect a causal effect of education. Empirical studies may be exposed to the problem of omitted-variable bias (or education endogeneity) if they ignore the possibility that the choices of educational attainment and social trust formation are simultaneously affected by unobserved factors, such as cognitive ability, personality traits, 
as well as family backgrounds and interactions in early life. ${ }^{2}$ Coleman (1988) also argues for a reverse causal direction, as trust attributes in early-life might also lead to better educational outcomes by allowing students to gain access to the help of family and fellow students. In this case, the estimate of the education effect does not reflect a real causal effect, but a spurious relation. A rigorous empirical study should be able to disentangle the real effect of education from the potential influences of confounding variables or present evidence to demonstrate that unobserved heterogeneity across individuals does not cause a substantial bias in the estimation.

In a large amount of literature, individual past life experience and perceptions of cultural and social structures are considered as two primary aspects of social trust at the individual level. Until now, however, little (if any) empirical evidence can be presented to clarify how education contributes to the building of social trust via these two sources. The theoretical rationales of the education effect remain untested and hypothetical.

This paper attempts to provide an inclusive examination of the role of college education in the formation of social trust. We employ econometric techniques to isolate the potential influences of confounding variables and quantify the exact degree of college effect. We also examine the potential mechanisms for the education effect by testing two hypotheses that are established in line with the two primary sources of social trust at the individual level:

\section{Hypothesis 1 College education promotes social trust via the heterogeneities (induced} by education disparities) in individual life experience/development.

Highly-educated people have more chance to do well economically, and generally live in a community where there are less heterogeneities (in the identity of social norms and conventions) and lower crime rates. They are less likely to be exposed to the "darker side" of society that has an adverse impact on the formation of social trust. With the cognitive and perceptual experiences from and outside academic programs, a college education increases the individual's capacity to communicate effectively and to socialize with others. People who have received a college education are more optimistic about controlling their own life-chances and engaging in close interaction with others, which leads to a higher belief in the benevolence of human nature in general, or at least a higher belief in the capacity of discerning and handling risks involved in trusting others.

Hypothesis 2 College education promotes social trust via the heterogeneities (induced by education disparities) in an individual's perceptions of cultural/social structures.

In a democratic society, college institutions have a civil mission—educating their students to be effective and responsible citizens. A college education increases individual knowledge of the cultural environment, economic environment, and legal environment. High educated people are more likely to share a social consensus on normative values that create an incentive to honor trust, and they are more affirmative of the competence and willingness of social arrangements in the enforcement of trustworthiness and fairness. College institutions also offer various opportunities where students can interact and cooperate with people from different social groups (in the procedure of acquiring knowledge). The between-group interaction

\footnotetext{
2 The meta-analysis by Huang et al. (2009) revealed that the problem of education endogeneity has received little attention in the empirical literature. Most studies include education as an exogenous independent variable and their estimates of the education effect are obtained by the OLS, probit or logit models. Moreover, most studies are focused on exploring contemporary sources of social trust. Their analyses include both education and contemporary variables (i.e. socioeconomic status, community or neighborhood characteristics, or life satisfaction) as independent variables. However, these contemporary variables are (endogenous) variables that are caused by educational attainment. Conditioning on such variables would block the part of the causal effect of education on social trust that acts through these variables (Pearl 2000).
} 
and cooperation may provide favorable information about the other group that would not otherwise be available (Kramer 2004, p. 152). They may enhance the perceived similarity and break down the conceptual boundaries between groups (Brewer and Kramer 1985), fostering a common knowledge that members of society share the same normative values. In general, a college experience expands the horizon of individuals on economic and social change, makes individuals more open-minded to accept otherness from heterogeneous groups, and makes individuals more affirmative of the trustworthiness of political and legal institutions.

\subsection{A Brief Illustration of the Evaluation Techniques}

We examine the causal effect of college education through the identification of the average treatment effect $(A T E)$, which is an econometric measure, generally adopted in medical trials or policy evaluation, for the average causal difference in outcomes between the treatment and the control group. The expression "treatment effect" refers to the causal effect of a given treatment or policy on an outcome variable of scientific or policy interest (i.e. the health of the patients or the income of the workers). The average treatment effect is the average of the individual treatment effects across the whole population of interest. In this paper, college education is the treatment and the ATE denotes the average expected causal effect of college education relative to lower education on individual social trust.

We apply the bivariate probit (BVP) and the control functions probit (CFP) methods to handle the potentially endogenous relation between choice of college education and social trust. ${ }^{3}$ The BVP method has been widely used in medical evaluation to reduce the bias due to self-selectivity in the binary treatment choice. The BVP is a simultaneous equation model that controls for endogeneity in the likelihood of the joint sets of the treatment and outcome distribution. Bhattacharya et al. (2006) have an inclusive comparison on the performances of the probit, two-stage probit (or two-stage least squares), and BVP. They show that the BVP is the only method to produce a consistent estimator when there is an endogenous treatment.

The control functions probit (CFP) model is a special case of the control functions (CF) model, which is generally applied to evaluate the treatment effect on continuous outcome by controlling directly for the correlation between the treatment choice and the unobservable heterogeneity in the outcome variable (Heckman and Navarro-Lozano 2004; Blundell et al. 2005). Because the probit specification can be derived from a model involving a latent variable with a linear expression, the CFP model produces a good approximation of the true ATE in a binary response model.

The CFP, like the BVP, allows one to identify the real causal effect, and one can examine the presence of treatment endogeneity. In general, an exclusion restriction is required in the CFP and the BVP approaches, especially when there is inadequate variation in the observable characteristics. ${ }^{4}$

\section{The NCDS Dataset and the Instrumental Variable Approach}

To investigate the development of social trust and the impact of college education, an appropriate data set is indispensable in order to follow the respondents through multiple

\footnotetext{
3 In a binary treatment framework where both the outcome and the treatment are a binary response variable, the general two-step procedure methods, such as two-stage probit or two-stage least squares, are not sufficient to provide a consistent estimate for ATE (Bhattacharya et al. 2006).

4 A detailed illustration of the BVP and CFP models and their identification strategy is presented in the Appendix of our working paper.
} 
life stages. The rich data of a British cohort born in 1958 from the National Child Development Study (NCDS) offers an opportunity to perform such an analysis. The NCDS is a multi-disciplinary longitudinal study of all those living in the UK (England, Scotland, and Wales) who were born in the week 3-9 March, 1958 (including immigrants who were born outside the UK). The first three sweeps were carried out by the National Children's Bureau in 1965, 1969 and 1974. The following three sweeps were carried out by the Centre for Longitudinal Studies (CLS) in 1985, 1991 and 1999-2000. The NCDS is widely used in economics, social and health sciences research to examine the patterns of human development that follow the lifespan.

Table 1 provides summary statistics of the main variables in this study. Information on social trust and information on college degree are extracted from the 1991 NCDS survey (the cohort members were 33 years old in 1991). The sample studied in this paper contains 10,441 observations. ${ }^{5} 67.3 \%$ of the cohorts indicate that most people can be trusted and $14.8 \%$ of the respondents has a college degree.

All covariates are extracted from the 1973-1974 survey (except for demographic information), during which the cohort members were 15-16 years old. They were approaching the end of compulsory education (secondary education was compulsory for all pupils between the ages of 11 and 16 in the UK). At that age they are faced with O/A-level examination(s) ${ }^{6}$ as well as a choice of further education.

Parental socioeconomic covariates include indicators of parental education level and parental economic class from the 1973-1974 survey. Other covariates of family background contain information of whether parent(s) changed (as a result of divorce, death etc.), length of time in the current address, and the number of siblings of the respondent.

Academic performance and motivation in adolescence are crucial predictors for the ultimate education outcome. They are also considered to be powerful determinants of social class and income in adulthood that directly affect the development of social trust. Yamagish (2003) believes social trust is a by-product of social intelligence, the ability to detect and process signs of risks in social interactions, which depends on cognitive resources. Using the teacher's report in the 1973-1974 survey, we collect information of respondents' performance in social studies and math, and whether they were absent from school for trivial reasons. We also collect, from the teacher's report, information of respondent's socializing behaviour (withdrawn score) in school, and information of certain school characteristics, such as school enrolment, teacher/student ratio, availability of facility resources, and attendance rate.

\subsection{Instrumental Variables}

The BVP and CFP methods require a valid instrumental variable in their estimation procedures. The instrumental variable should have the property that its variation is associated

\footnotetext{
5 The sample size in birth survey is 17,409 , but there is attrition among each survey, only $11,000-12,000$ observations remain since the 1973-1974 survey. Attrition and missing data do not appear to be systematically associated with the distribution of the key covariates and they not affect our estimation results (a detailed discussion can be found in the Appendix of the working paper of Case et al. (2005) and the Appendix of our working paper.

6 The General Certificate of Education or GCE is a secondary-level academic qualification that Examination Boards in the United Kingdom confer to students. The GCE traditionally comprised two levels: the Ordinary level (O-level) and the Advanced level (A Level). The A-level is usually taken by students during the optional final two years of secondary school (years 12 and 13, usually ages 16-18). The qualification is used as a sort of entrance exam for some universities. O-level was introduced as part of British educational reform in the $1950 \mathrm{~s}$ alongside the more in-depth and academically rigorous A-level.
} 
Table 1 Descriptive statistics of the main variables

\begin{tabular}{llll}
\hline Variable & $\mathrm{N}$ & Mean & SD \\
\hline $\begin{array}{l}\text { Outcome variable (age 33) } \\
\quad \text { Social trust }\end{array}$ & 10,441 & .672 & .470 \\
$\begin{array}{l}\text { Treatment variable (age 33) } \\
\text { College education }\end{array}$ & 10,441 & .148 & .355 \\
Basic demographics (birth) & & & \\
Male & 10,441 & .483 & .500 \\
Minority-non white & 10,392 & .025 & .156
\end{tabular}

Social studies performance in class (age 15-16)

$\begin{array}{llll}\text { Excellent } & 7,457 & .147 & .354 \\ \text { Above average } & 7,457 & .231 & .422 \\ \text { Average } & 7,457 & .334 & .471 \\ \text { Below average } & 7,457 & .143 & .350 \\ \text { Lowest level } & 7,457 & .115 & .319\end{array}$

Math performance in class (age 15-16)

$\begin{array}{llll}\text { Excellent } & 7,999 & .124 & .330 \\ \text { Above average } & 7,999 & .224 & .417 \\ \text { Average } & 7,999 & .351 & .477 \\ \text { Below average } & 7,999 & .167 & .373 \\ \text { Lowest level } & 7,999 & .130 & .337\end{array}$

Residence region (age 15-16)

$\begin{array}{llll}\text { England (non-London) } & 9,935 & .652 & .476 \\ \text { London } & 9,935 & .179 & .383 \\ \text { Scotland } & 9,935 & .103 & .305 \\ \text { Wales } & 9,935 & .056 & .231\end{array}$

Father economic status (age 15-16)

\begin{tabular}{lccc} 
Professional & 7,165 & .059 & .236 \\
Managerial & 7,165 & .212 & .409 \\
Non-manual-skilled & 7,165 & .101 & .302 \\
Manual-skilled & 7,165 & .431 & .495 \\
Non-manual-semi & 7,165 & .014 & .116 \\
Manual-semi & 7,165 & .125 & .331 \\
Unskilled & 7,165 & .045 & .306 \\
Mother economic status (age $15-16)$ & & \\
Professional & 7,658 & .003 & .056 \\
Managerial & 7,658 & .110 & .313 \\
Non-manual-skilled & 7,658 & .219 & .414 \\
Manual-skilled & 7,658 & .047 & .212 \\
Non-manual-semi & 7,658 & .117 & .322 \\
Manual-semi & 7,658 & .101 & .302 \\
Unskilled & 7,658 & .063 & .243 \\
\hline
\end{tabular}

with change in educational attainment, but does not lead to change in the social trust, aside from the indirect route via educational attainment. In other words, an exclusion restriction is imposed for the instrumental variable. We construct such an instrument from the 
information of the length of schooling absence due to illness (or the absence length for brevity), which is also reported in the 1973-1974 survey. From our perspective, the length of schooling absence due to illness can be decomposed into systematic components and non-systematic components. The systematic components arise from inherited health status and family background, such as living conditions, nutrition intake, parental socioeconomic status, and the roles of parents in the family. The systematic components are expected to have a lasting influence over the lifespan, impacting education achievement and possibly the level of social trust in adulthood.

The non-systematic components arise from haphazard events, such as accidents, illness (cold or throat) due to unexpected weather changes and other incidents. For students with poor health or chronic conditions, class cancellation/re-arrangement due to adverse weather or provisional change in school programs can also been seen as the cause of the non-systematic components, in the sense that these students might have been absent from school in the original class arrangement. The non-systematic components are not supposed to have a lasting health influence over the lifespan, and they should not have any direct impact on the level of social trust in adulthood.

Because of the timing of its occurrence, both the systematic and non-systematic components of the absence length are strongly correlated with the respondent's grades at the A-level exams, and subsequently their chance of receiving higher education. A valid exclusion restriction is obtained for social trust if the non-systematic components can be separated from the systematic components. We achieve this design by regressing the absence length on relevant information and breaking down the dependent variable. Family background, parental socioeconomic status, and adverse health information in early life (chronic illness, low birth weight, maternal smoking during pregnancy, etc.) are included in the regression to decompose the absence length. Besides, dummy variables are created for each type of systematic illness reported for the schooling absence except for cold, throat, periods, accidents or injuries, and interacted with other adverse health factors in the regression of the absence length. The intuition is that, if an individual has certain health problems, and misses some school days because of non-accidental or chronic illness, it is highly plausible that these interactions capture some systematic health problems.

One may expect that a student might play truancy from school in the name of illness because of their distaste for schooling or poor relations with other school children, and consequently, the predicted residuals might not be excluded from the equation of social trust. We believe that this should not be a problem because in the decomposition process we will control for the teacher's perspective of the truancy frequency of the students. Moreover, all covariates in the equation of social trust, i.e. academic performance in math and social studies, (unsociable) relations with other children, and information of school resources are included in the decomposition of the absence length. The rich information included in the decomposition process should minimize the potential influence of fabricated illness on the validity of the non-systematic components.

As relevant covariates are included in the regression of the absence length, we obtain its predicted value-ideally the systematic components, and its predicted residual valueideally the non-systematic components and the instrumental variable. Statistical proof of the validity of the instrumental variable is presented in Table 2. Part A of Table 2 provides the test statistics for the correlations between the respondent's contemporary health indicators (at age 33) and the predicted residual value of the absence length. For comparison, similar correlation tests are also performed for the absence length and for the predicted value of the absence length. It is straight-forward that the absence length and its predicted value are strongly correlated with contemporary health status and chronic conditions, while 
Table 2 Test statistics on the validity of the instrumental variable

\begin{tabular}{|c|c|c|c|c|c|c|}
\hline & \multicolumn{2}{|c|}{ Absence length } & \multicolumn{2}{|c|}{ Systematic term } & \multicolumn{2}{|c|}{ Non-systematic term } \\
\hline & Coef. & $p$-value & Coef. & $p$-value & Coef. & $p$-value \\
\hline \multicolumn{7}{|l|}{ A. Correlation with mid-life health } \\
\hline General health status at $32-33$ & -.10 & .00 & -0.10 & .00 & -.01 & 0.38 \\
\hline No. Chronics suffered at 32-33 & .11 & .00 & 0.16 & .00 & .01 & 0.40 \\
\hline No. Chronics ever suffered & .13 & .00 & 0.18 & .00 & .01 & 0.23 \\
\hline \multicolumn{7}{|l|}{ B. Correlation with residuals of trust } \\
\hline Trust residuals unrelated to exams & -.03 & .01 & -.04 & .00 & -.01 & 0.66 \\
\hline
\end{tabular}

Indicator of general health status has 4 categories: 0-poor, 1-fair, 2-good, 3-excellent

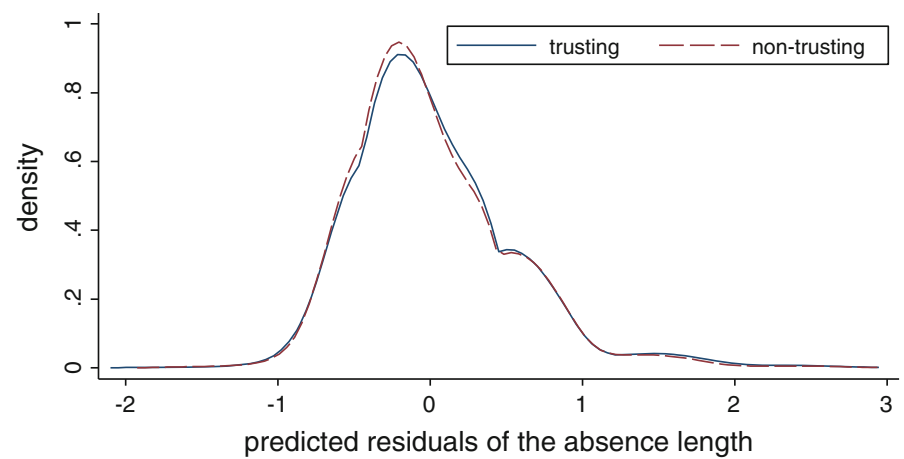

Fig. 1 Kernel density of the instrument for trusters and non-trusters in the group without college degree

the instrument has no significant correlation. These statistics provide strong support for the design principle adopted in this research that the non-systematic components are not supposed to have a lasting health influence over the life span.

Part B of Table 2 provides evidence for our argument that the predicted non-systematic components of the absence length have an impact on social trust only via individual's exam grades (and thus choice of college education). We break down the trust outcome by the number of A-levels that the respondent has passed (which is an important qualification for college entrance in the UK) by age 20. Then we perform a correlation test for the instrument and the residual value of the trust outcome unrelated to the number of passed A-levels. Similar correlation tests are applied for the absence length and for the predicted systematic components of the absence length. Once again the absence length and its predicted value are strongly correlated with the residual value of the trust outcome unrelated to the number of passed A-levels, while the instrument has a negligible correlation with the residual value of the trust outcome.

Figures 1 and 2 offer additional proof of the validity of the instrumental variable. Figure 1 depicts the kernel density of the residual value of the absence length for trusters and non-trusters in the group without college degree. Figure 2 depicts the kernel density of the residual value of the absence length for trusters and non-trusters in the group with a college degree. Provided that the instrument only impacts social trust via education choice, the kernel densities of the residual value of the absence length should not be diverting for trusters and non-trusters in the same education group. It is straight-forward in Fig. 1 and 2 


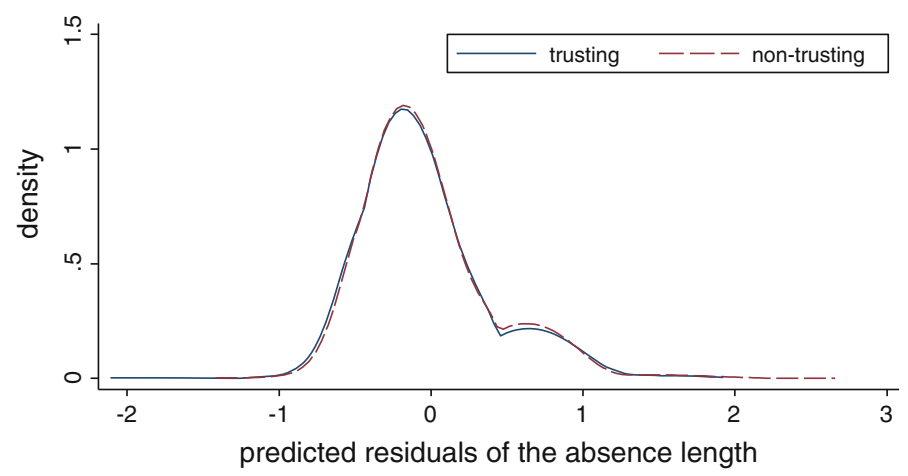

Fig. 2 Kernel density of the instrument for trusters and non-trusters in the group with college degree

Table 3 Estimates of ATE and endogeneity test

The coefficients are reported as probability change

* Significant at the $10 \%$ level *** Significant at the $1 \%$ level

\begin{tabular}{|c|c|c|c|}
\hline & \multicolumn{2}{|c|}{$A T E$ estimation } & \multirow{2}{*}{$\begin{array}{l}\text { Endogeneity test } \\
p \text {-value }\end{array}$} \\
\hline & $A T E$ & SE & \\
\hline Baseline probit & $.123 * * *$ & .012 & - \\
\hline Full-specification probit & $.074 * * *$ & .014 & - \\
\hline BVP & .077 & .048 & .923 \\
\hline CFP & $.077 *$ & .047 & .921 \\
\hline
\end{tabular}

that the kernel densities are overlapping for the same education group. Therefore the distribution of the residual value of the absence length does not vary between trusters and non-trusters and can be regarded as an applicable exclusion restriction (or instrumental variable) for the outcome of social trust.

\section{Results from the Empirical Examinations}

\subsection{Identification of ATE}

As a first step in our empirical study, we employ the probit, bivariate probit (BVP) and the control functions probit (CFP) to quantify the causal effect, in terms of ATE, of college education on individual social trust. The findings from these evaluation methods are presented in Table 3. In the baseline probit, which includes demographic characteristics, residence region, and family composition as control variables, we observe a strongly significant estimate of the college effect. The estimated coefficient of ATE is .123 ( $p$-value $<.001)$ in terms of probability change. This indicates that the level of social trust of those with college degree, other conditions (in early life) being equal, exceeds that of those without a college degree by $12.3 \%$ age point. In other words, a college education increases the probability of trusting generalized others by one-fourth of its standard deviation. In the full-specification probit, where parental socioeconomic status, academic performance, report of school truancy and personality strength are added in the equation, the estimated coefficient of ATE drops from .123 to .074, although the latter remains statistically significant ( $p$-value $<.001)$. 
Since the choices of educational attainment and the development of social trust can be simultaneously affected by some individual characteristics that are not observable, the probit estimator may suffer an omitted-variable bias. We employ the endogeneity models, namely, the BVP and CFP methods, to identify the real causal effect through the exogenous variation in educational attainment induced by the instrumental variable - the predicted non-systematic components of the absence length. The estimated ATE coefficient is .077 in both the BVP method and the CFP method. They do not differ from the coefficient identified by the full-specification probit.

The trivial correlation between college education and the unobservable heterogeneity in social trust, according to the endogeneity test in the BVP and CFP models ( $p$-value $>.9$ ), suggest that omitting-variable bias is not a severe problem in the estimation of the college education effect. The rich information of early-life development, especially parental socioeconomic status, academic performance, and unsociable behavior in adolescence, is the key for reducing the probability of unobserved characteristics in childhood and adolescence simultaneously impacting educational attainment and social trust. ${ }^{7}$

The results from the ATE identification indicate that the level of social trust of college graduates exceeds that of non-college graduates by $7.5 \%$ point. This implies that a college education increases the probability of trusting others by about $16 \%$ of its standard deviation. The regression statistics in the first step of our empirical study confirm the significance of college education in the formation of social trust. ${ }^{8}$ However, these statistics cannot provide any clear mechanisms to explain how college education contributes to the building of social trust. The theoretical expectations about the role of education remain hypothetical and untested

\subsection{The Investigation of the Hypothetical Mechanisms}

The findings from the first step of our empirical study do not clarify how college education fosters social trust. In the second step we use contemporary information to examine whether individual experience/development and individual perceptions of cultural/social structures are primary channels in the causal linkage between college education and social trust.

The contemporary variables applicable to the hypothetical channels are drawn from the 1991 survey, the same survey from which information on social trust is collected. As presented in Table 4, these contemporary variables of the NCDS observations are classified into 3 categories: Category i-characteristics of life experience/development since adulthood; Category ii-views on the status of social norms and conventions; and Category iii-views on the competence and motives of formal/institutional arrangements in the enforcement of trustworthiness. Contemporary variables in category ii and category iii represent the heterogeneities in individual perceptions of cultural and social structures. We

\footnotetext{
7 Some early-life covariates appear systematically significant in the equation of social trust across all evaluation methods. The estimates of these early-life covariates do not necessarily reflect the true causal effects or the direct influences on individual social trust. These covariates are included in the regression to reduce omitted-variable bias in the ATE estimate and to assure the conditional validity of the instrumental variable. We present the regression statistics of the key covariates in Table 6 of Appendix A, in concern of the possibility that the estimates of these early-life variables can provide some information on the formation of social trust for researchers in relevant areas.

${ }^{8}$ Sensitivity tests (presented in the Appendix of our working paper in view of the length of this paper) indicate that the $A T E$ estimates are robust to measurement error in educational attainment and sample attrition in the dataset.
} 
Table 4 Contemporary variables for the examination of the hypothetical mechanisms
i. Indicators of Life experience and
a. Economic class of the first job; development since of adulthood
b. Economic class of current/last job;
c. Respondent and his/her partner have debt;
d. Happiness, all things considered;
e. Currently married and remained in the first marriage*;
f. Capacity in handling/avoiding argument.

ii. Views of the status of social norms a. The young are losing respect on traditional values; and conventions (Optimistic vs. pessimistic)

b. Would not mind if the neighbor is from other race;

c. Law breaker should be given stiffer sentences;

d. Death penalty is the most appropriate sentence for some crimes.

iii. Views of the competence and willingness of social arrangement in the enforcement of trustworthiness (Optimistic vs. pessimistic) a. Ordinary people have no say in what government does;

b. One law exists for the rich and one law exists for the poor;

c. No political party would benefit people like the respondent;

d. Government not doing enough in redistributing wealth.

* Respondents also reported in the 1991 survey their satisfaction of current relationship. Since this variable has an identical say as (and it can be used to substitute) the indicator of respondents' marital status in the investigation of the hypothetical mechanisms, it is not included as one of the indicators in category $i$

classify them into two categories to distinguish the informal contextual characteristics from the formal contextual characteristics.

The category of individual life experience/development since adulthood includes 6 indicators: economic class of the first job after schooling; economic class of the current job or economic class of the last job for those currently not in the job; debt status of the respondents and their partner; sense of happiness with all things being considered; marital status of the respondents (whether they have been married and remained in the first marriage); and sense of the capacity in avoiding arguments. The information transmitted by these variables enables us to explore whether college graduates have a higher belief in the benevolence of human nature in general, or at least a higher belief in the capacity of discerning, handling and taking risks in social interactions, for the reason that they are more likely to stay in a well-to-do environment, more effective in integrating into close interaction with others, and more optimistic of controlling their own life-chances.

The category of individual views of the status of social norms and conventions includes 4 indicators: concern about whether the young are losing respect for traditional values; concern of whether the neighbor is from another ethnic origin; concern about whether law breaker should be given stiffer sentences; concern about whether the death penalty is the most appropriate sentence for some crimes. These indicators offer information about the respondents' confidence of social consensus on normative values, tolerance of otherness from heterogeneous group, and their dependence of formal/institutional arrangements as substitute of the informal constraints in the enforcement of trustworthiness.

The category of individual views of the competence and willingness of formal/institutional arrangements includes 4 indicators: sense of people like me (the respondent) having no say in what government does; sense of the existence of two different laws for the rich and for the poor; and sense of no political party being beneficial to people like me (the respondent); and sense of government doing enough to ensure fairness in the wealth distribution. These indicators offer information on the respondents' confidence of the reliability and goodwill of formal structural or institutional arrangements in protecting the interest of generalized people and ensuring fairness in the enforcement procedure. 
The information contained in category ii and category iii enables us to investigate whether a college experience expands people's horizon on economic and social change, improves their understanding of the existing social values, makes them more open-minded to accept otherness from heterogeneous groups and more affirmative of the competence and fairness of institutional arrangements, and subsequently leading to a higher trust in people in general.

In the investigation of the hypothetical channels, each contemporary variable is introduced separately into the original probit regression of social trust, with all early-life covariates remaining in the equation. ${ }^{9}$ We examine the change in the estimated ATE of college education due to the introduction of the contemporary variables. If, for example, college education is a key determinant of life happiness in adulthood and the variation of life happiness, on account of education differences, is strongly and positive associated with the variation in social trust, the introduction of life happiness in the original full-specification probit regression should pick up, at least partially, the causality from college education to social trust. We should then expect a substantial drop in the estimate of the college effect.

Table 5 presents the ATE estimates after we introduce each contemporary variable separately into the full-specification probit model. ${ }^{10}$ Controlling for the heterogeneities in contemporary life development does not have any noticeable impact on the estimates. These six estimates range from .072 to .074 , and three of them are precisely .074 , which are exactly the same as the estimate identified by the full-specification probit model (see Table 3).

We observe a substantial drop in the estimates following the introduction of contemporary variable in category ii (views of social norms and conventions). These four estimates range from .046 to .059 , which are $20-40 \%$ smaller than the estimate identified by the full-specification probit model. It turns out that lower-educated people are more reluctant to accept in the neighborhood a family from another ethnic origin, they are more pessimistic about the significance of the existing social values, and they have a higher preference for stiffer laws, or even the death penalty as a protective assurance against the perceived risks of noncompliance of social norms and extreme non-cooperative behavior.

Controlling for the contemporary variables in category iii (views of formal or institutional arrangements) causes a moderate drop in the estimates. The views of the impartiality and fairness in legal system and the views of the performance of government in distributing wealth have a trivial effect on the estimates of $A T E$, while the views of the government or political parties (in terms of representing the interest of people in general) lead to $12-15 \%$ drop in the estimates.

For a more perceptual comparison, we present in Fig. 3 bar graphs for the estimate of $A T E$ obtained from the original probit model in which no contemporary variable is included, and from the augmented-probit model in which the entire set of contemporary variables in category i, category ii, and category iii are included separately as covariates. It is straight-forward that controlling for the entire set of category i indicators only causes a negligible change in the estimated ATE, while controlling for the entire set of category ii indicators and category iii indicators reduces the estimate by $60 \%$ (from .074 to .029) and $30 \%$ (from .074 to .051), respectively. Information contained in category ii and category iii

\footnotetext{
${ }^{9}$ We use the probit model in this investigation because it is confirmed in the previous section that there is no sign of omitted-variable bias in the identification of ATE, when a rich set of early-life information has been controlled for.

10 To avoid the potential problem of "bad covariates", we have also investigated the variation of the educational effect on the residuals that cannot be explained by the contemporary variables in each category. The findings (in terms of standardized coefficients) are identical to the results presented in Table 5.
} 
Table 5 Estimates of the college effect after controlling for contemporary variable

\begin{tabular}{|c|c|c|c|}
\hline & ATE & SE & $\mathrm{N}$ \\
\hline \multicolumn{4}{|l|}{ Category i: individual life experience/development since adulthood } \\
\hline Economic class of the first job (including housework) & $.074 * * *$ & .014 & 10,441 \\
\hline Economic class of current/last job & $.072 * * *$ & .014 & 10,441 \\
\hline Respondent and his/her partner have debt & $.073 * * *$ & .014 & 10,280 \\
\hline Happiness, all things considered & $.074 * * *$ & .014 & 10,283 \\
\hline Currently married and remained in the first marriage & $.074 * * *$ & .014 & 10,298 \\
\hline Capacity in handling/avoiding argument & $.075 * * *$ & .014 & 10,411 \\
\hline \multicolumn{4}{|l|}{ Category ii: Views of the status of social norms and conventions } \\
\hline Would not mind if the neighbor family are from other race & $.059 * * *$ & .014 & 10,405 \\
\hline The young are losing respect on traditional values & $.052 * * *$ & .015 & 10,359 \\
\hline Death penalty is appropriate for some crimes & $.046^{* *}$ & .015 & 10,410 \\
\hline Law breaker should be given stiffer sentences & $.055^{* * *}$ & .015 & 10,363 \\
\hline \multicolumn{4}{|c|}{ Category iii: Views of the competence and motives of formal and institutional arrangement } \\
\hline Ordinary people have no say in government & $.064 * * *$ & .014 & 10,332 \\
\hline Different laws exist for the rich and for the poor & $.070 * * *$ & .014 & 10,388 \\
\hline No political party would benefit me & $.063 * * *$ & .014 & 10,353 \\
\hline Government not doing enough in redistributing wealth & $.072 * * *$ & .014 & 10,378 \\
\hline
\end{tabular}

** Significant at the $5 \%$ level

*** Significant at the $1 \%$ level

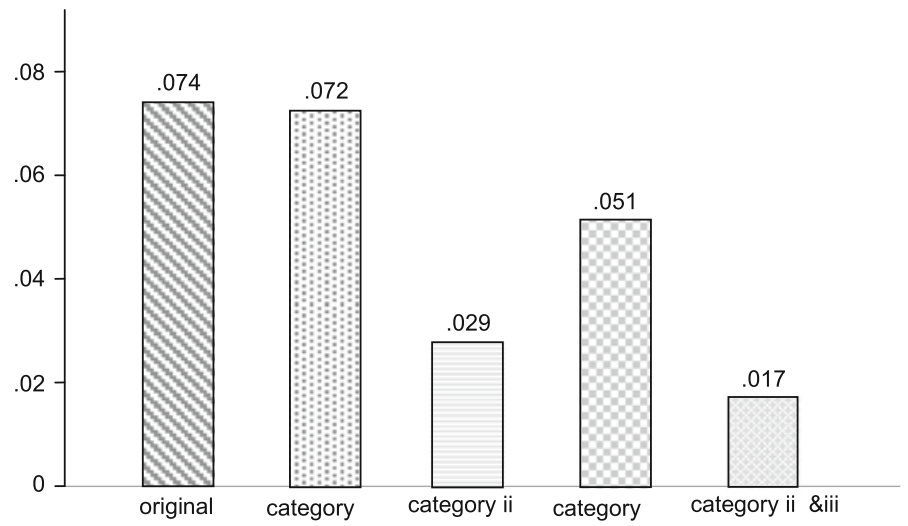

Fig. 3 Bar graph for the college effect

depict individual perceptions of cultural and social structures. Controlling for both category ii and category iii in the regression reduces the estimate of ATE by $77 \%$ (from .074 to .017 , presented as the fifth bar in the figure). These findings suggest that a college education experience enhances the perceived similarity and breaks down the conceptual boundaries between social groups. College education is an effective approach in fostering a social consensus on normative values that create an incentive to honor trust (60\% of the estimated causal effect acts through the heterogeneities in social norms and conventions). 
Our investigation provides substantial evidence to support the hypothesis that individual perceptions of cultural and social structures are the key channel in the causal linkage between college education and social trust.

\subsection{Early-Life Backgrounds Versus Contemporary-Life Development}

Our investigation based on contemporary variables indicates that individual life experience/development since adulthood is not a key channel in the causal connection between college education and social trust. We take efforts to give an illustration on the raison d'être underlying this somewhat unexpected finding.

Individual life experience is strongly associated with social trust in theoretical and empirical literature on social trust (Brehm and Rahn 1997; Offe 1999; Hardin 2003; Alesina and La Ferrara 2000, 2002; Paxton 2007). Our study also has similar findings. We use the probit model to regress social trust exclusively on the entire set of category $\mathrm{i}$ indicators. We repeat this procedure for category ii indicators and for category iii indicators. The estimates of each set of these indicators have strong statistical significance. The pseudo-R squares obtained from the probit estimation are also similar for these three categories, which indicates that contemporary variables in category $\mathrm{i}$ have the same explanatory power as those in category ii or category iii.

Endogeneity models are employed to evaluate the causal effects of college education on the heterogeneities in contemporary-life development. We observe a substantial and positive influence of college education on economic condition and personal happiness. College education only has a trivial effect on marital status (or satisfaction with marriage) and capacity in handling arguments (detailed findings are presented in Appendix B).

At first glance, we are confronted with a paradox: individual life experience and development since adulthood have a negligible role in the causal pathway from college education to social trust, although education disparities are making a large difference in socioeconomic status and perceived happiness, and these factors are strongly associated with social trust.

We obtain some insight in this paradox by an exploration of the development of social trust in early life. Trust can be learned in early life and persists as part of a core personality trait, unless challenged by trauma (Uslaner 2002, pp. 160-90; Stolle 2002). Family background and environmental influences are considered to have a direct and lasting impact on social trust at the individual level. It is also widely believed and well documented that the heterogeneities in family and environmental parameters are a major source of the variations in the socioeconomic outcomes of children. Therefore, we claim that the association between contemporary-life success (economic conditions, social class and life happiness) and social trust reflects, at least partially, the lasting effect of early-life factors on individual development and social trust in the life course. When a large proportion of the correlation between contemporary-life success and social trust is attributable to the lasting effect of childhood and adolescent experience, college education may not have much causal influence on social trust via its power in promoting individual development in adulthood.

To support our argument, we break down the outcome variable of social trust with early-life information by a probit model. ${ }^{11}$ The residual variable of social trust denotes the variations of social trust that cannot be explained by early-life information. Provided that

\footnotetext{
11 The early-life information comprises information on childhood experience and information on adolescence experience. We include all covariates in the previous analysis (except for educational attainment), which are reported in the 1973-1974 survey, as indicator of adolescence experience or development. We
} 
Table 6 Evidence of the lasting effects of early-life backgrounds on the development of social trust

\begin{tabular}{|c|c|c|c|c|}
\hline \multirow[t]{2}{*}{ Development/success since adulthood } & \multicolumn{2}{|c|}{$\begin{array}{l}\text { Residual variable } \\
\text { of social trust }\end{array}$} & \multicolumn{2}{|c|}{$\begin{array}{l}\text { Outcome variable } \\
\text { of social trust }\end{array}$} \\
\hline & Coef. & $p$-value & Coef. & $p$-value \\
\hline Economic class of the first job & .00 & .88 & .06 & .00 \\
\hline Economic class of current/last job & .01 & .57 & .06 & .00 \\
\hline Respondent and his/her partner have no debt & .01 & .18 & .02 & .03 \\
\hline Happiness, all things being considered & .06 & .00 & .09 & .00 \\
\hline
\end{tabular}

current-life status has a direct and strong effect on social trust, which is not attributable to the lasting effect of childhood experience and adolescence experience, we should expect a strong correlation between the residual variable and the contemporary variables of currentlife success (economic conditions, social class and life happiness). As shown in Table 6, it turns out that economic class and conditions have no statistically meaningful correlation with the residual variable of social trust that cannot be explained by the early-life variables, albeit that they have a very strong correlation with the outcome variable of social trust. Current sense of happiness remains strongly associated with the residual variable, but the correlation coefficient drop by $1 / 3$.

Table 6 indicates that a large proportion of the correlations between indicators of development/success since adulthood (especially for past and current economic class) and social trust are indeed attributable to the lasting effect of experiences formed in childhood and adolescence. It suggests that college education has little causal influence on social trust via its power in promoting development in adulthood.

\section{Conclusion}

In this paper we have explored the role of college education in the formation of social trust, using the rich data of a British cohort. The theoretical review on the micro aspects of social trust considers risks as an essential element and emphasizes life experience/development and perceptions of cultural/social structures as two primary sources of social trust at the individual level. In the empirical study, we quantify the causal effect of college education and we test the validity of the hypothetical mechanisms in the causal pathway from college education to social trust.

Isolating the influences of confounding variables is the key to quantify the causal effect of college education. Empirical studies may be exposed to the problem of omitted-variable bias (or education endogeneity) if they ignore the possibility that the choices of educational attainment and social trust formation are simultaneously affected by unobserved factors. To identify the overall causal effect of college education, we should not include contemporary indicators of individual development or individual perceptions of cultural/social structures as the explanatory variables. These contemporary indicators are subject to the influences of educational attainment and conditioning on such variables would block the part of the causal effect of education experience that acts through these variables.

Footnote 11 continued

also include similar variables reported in the 1969 survey as indicator of childhood experience or development. 
In the first part of the empirical analysis we identify the average treatment effect (ATE) of college education, with an emphasis on tackling education endogeneity. Strong evidence is found to support the substantial role of college education in promoting individual social trust. We show that the rich information of adolescent development and experience is crucial in reducing omitted-variable bias. The estimate obtained from the baseline probit, in which we do not controlled for information of parental socioeconomic status, cognitive capability, academic motivation, and personality strength in adolescence, is $66 \%$ larger than the estimates obtained from the full-specification probit and endogeneity models. Lack of information of adolescence development and experience indeed causes a upward omitted-variable bias in the estimation.

Using the measurement adopted in the meta-analysis (Huang et al. 2009), the base-line probit in this study indicates that one additional year of schooling increases individual social trust by $4.4 \%$ of its standard deviation. The full-specification probit and endogeneity models indicate that one additional year of schooling increases individual social trust by merely $2.6 \%$ of its standard deviation. The base-line probit model produces an estimate that is equal to the synthesized education effect (which is $4.6 \%$ of the standard deviation in our meta-analysis) on the existing studies of social trust. Since most of the existing studies do not consider education as an endogenous variable and cannot control for information of early-life development, their estimations are not different from our base-line probit estimation and the estimates, as a consequence, are exposed to a substantial upward bias.

In the second part of the empirical analysis we examine the change in the estimate of $A T E$ due to the introduction of individual information of contemporary-life experience/ development and contemporary perceptions of cultural/social structures. The hypothesis that individual experience is a key channel from college education to social trust fails to find support in the investigation. There is a negligible change in the estimates of the ATE due to the introduction of economic conditions, personal happiness, marriage status, and capacity in effective interactions with others. Our further analysis shows that a large proportion of the associations between contemporary-life success and social trust are indeed attributable to the lasting effect of experiences formed in childhood and adolescence.

Individual understanding of cultural and social structures explains $77 \%$ of the college effect on social trust. College education promotes individual social trust because it plays a positive and fundamental role in expanding the horizon of individuals on economic and social change, making individuals more open-minded to accept otherness from heterogeneous groups, and inspiring consensus on normative values and affirmative attitude toward institutional arrangements.

This paper contribute to the research of social trust in four aspects:

Firstly, our study provides strong econometric evidence to support the positive role of college education in the building of social trust. Although education has been commonly believed to be one of the most important determinants of social trust at the individual level, little evidence has been presented to quantify the causal effect of college education. Our study shows that a college education increases one's probability of trusting generalized others by about $16 \%$ of its standard deviation.

Secondly, previous studies have not, in general, provided an estimate of the true causal effect of education. The majority of these studies consider education as an exogenous independent variable and they were not able to control for information on early-life development. Combining results from this study and our previous meta-analysis, we show that there is a roughly $70 \%$ upward bias in the estimate of education when empirical studies fail to control for early-life information and education endogeneity in the estimation. 
Thirdly, our study verifies that individual understanding of cultural and social structures is the primary channel in the causal linkage between college education and social trust. The theoretical rationale that college education promotes social trust via its effect on later-life experience/development fails to find support in our study.

Fourthly, our study indicates that the strong association between contemporary-life success or happiness and contemporary level of social trust might largely reflect the lasting effect of early-life factors on later life development. A development perspective on social trust enables researchers to gain a better understanding of the development of social trust at the individual level.

Open Access This article is distributed under the terms of the Creative Commons Attribution Noncommercial License which permits any noncommercial use, distribution, and reproduction in any medium, provided the original author(s) and source are credited.

\section{Appendix}

Appendix A: Coefficients of Early-Life Covariates in the Regression of Social Trust

Some early-life covariates appear systematically significant in the equation of social trust across all evaluation methods. The estimates of these early-life covariates do not necessarily reflect the true causal effects or the direct influence on individual social trust. However, the estimates of early life factors should provide some information on the formation of individual social trust that can be interesting for some researchers in related areas. We present the regression statistics of the key covariates in Table 7.

Above all, there are substantial differences in demographic characteristics in trusting general people. Men are more reluctant to give a positive response, and white people are more likely to be trustful. It turns out that ethnic group and college education are the most strongest predictor of social trust in adulthood.

The education level of father is a statistically significant variable in the regressions. Adolescents who displayed withdrawn behavior in adolescence would have a significantly

Table 7 Regression statistics of key covariates in the estimations of social trust

\begin{tabular}{|c|c|c|c|c|c|c|}
\hline & \multicolumn{2}{|l|}{ Probit } & \multicolumn{2}{|l|}{ BVP } & \multicolumn{2}{|l|}{ CFP } \\
\hline & Coef. & SE & Coef. & SE & Coef. & SE \\
\hline Male & $-.056^{* * *}$ & .010 & $-.059 * * *$ & .010 & $-.056 * * *$ & .010 \\
\hline Non-white & $-.146^{* * *}$ & .034 & $-.155^{* * *}$ & .034 & $-.146^{* * *}$ & .034 \\
\hline Father age on leaving school & $.011 * *$ & .004 & $.008 *$ & .004 & $.011 * *$ & .004 \\
\hline Self-rated relation with mother & $-.028 * * *$ & .007 & $-.027 * * *$ & .007 & $-.028 * * *$ & .007 \\
\hline Parent change since birth & $-.057 * * *$ & .022 & $-.057 * * *$ & .022 & $-.057 * * *$ & .022 \\
\hline Withdrawn (unsociable) score & $-.013 * *$ & .005 & $-.013 * *$ & .005 & $-.013 * *$ & .005 \\
\hline Math rating in class & $.023 * * *$ & .007 & $.019 * *$ & .008 & $.023 * * *$ & .007 \\
\hline $\mathrm{N}$ & 10,441 & & 10,441 & & 10,441 & \\
\hline
\end{tabular}

The coefficients are reported as probability change

* Significant at the $10 \%$ level

** Significant at the $5 \%$ level

*** Significant at the $1 \%$ level 
lower probability to trust general people in their adulthood. Traumatic experience in early life, such as parent change due to divorce or death etc., strongly inhibit the formation of social trust.

Academic performance in math is statistically significant in the regression of social trust. This significant coefficient may reflect the real causal effect of cognitive capacity. Yamagish (2003), for example, consider social trust as a by-product of social intelligence. However, these coefficients may also reflect the influence of socio-ecologically-based interventions in early life that simultaneously affect cognitive development and social trust development.

Appendix B: Estimation results of the Causal Effect of College Education on Individual Experience/Development Since Adulthood

Endogeneity model is employed to evaluate the causal effect of college education on the contemporary variables about individual life experience. Note that economic class of the first job or current job is an ordinal variable with 6 categories, and the other four contemporary variables of individual experience are binary variables. When the outcome variable is a binary variable, we use control functions probit (CFP) method to identify the causal effect of college education; when the outcome variable is an ordinal variable, we use control functions (CF) method. As a comparison, we also present the results from the simple model (OLS or probit) estimations. The evaluation results are presented in Table 8.

In the simple model (OLS or probit) estimations, college education has a strong association with past or current economic class $(p$-value $<.001)$. There is a substantial drop in these coefficients after we take into account the endogeneity of educational attainment, although college education is still one of the strongest determinants of past or current economic class.

Table 8 Estimates of the college effect on contemporary variable

Coef. SE $\quad \begin{aligned} & \text { Endogeneity } \\ & (p \text {-value })\end{aligned}$

\begin{tabular}{|c|c|c|c|c|}
\hline \multicolumn{5}{|l|}{ A. Simple model (OLS or probit model) } \\
\hline Economic class of the first job (including housework) & $.523 * * *$ & 0.045 & - & 8,724 \\
\hline Economic class of current/last job & $.774 * * *$ & 0.037 & - & 9,846 \\
\hline Respondent and his/her partner have debt & -0.022 & 0.015 & - & 10,280 \\
\hline Happiness, all things being considered & -0.006 & 0.015 & - & 10,283 \\
\hline Currently married and remained in the first marriage & -0.007 & 0.015 & - & 10,298 \\
\hline Capacity in handling/avoiding argument & -0.018 & 0.012 & - & 10,411 \\
\hline \multicolumn{5}{|l|}{ B. Endogeneity model (CF or CFP model) } \\
\hline Economic class of the first job (including housework) & 0.244 & 0.156 & 0.061 & 8,724 \\
\hline Economic class of current/last job & $.317 * *$ & 0.015 & 0 & 9,846 \\
\hline Respondent and his/her partner have debt & $-.118 * *$ & 0.047 & 0.042 & 10,280 \\
\hline Happiness, all things considered & $.128 * *$ & 0.056 & 0.011 & 10,283 \\
\hline Currently married and remained in the first marriage & 0.066 & 0.05 & 0.139 & 10,298 \\
\hline Capacity in handling/avoiding argument & 0.036 & 0.043 & 0.649 & 10,411 \\
\hline
\end{tabular}

** Significant at the $5 \%$ level

*** Significant at the $1 \%$ level 
The results from the simple model estimations show that college education has a trivial association with personal/family debt or personal happiness. The results from the endogeneity model estimations, however, indicate that college education is effective in improving personal/family economic condition and promoting sense of happiness. The null hypothesis of exogenous choice of college education is rejected by the endogeneity test.

College education has a trivial influence on marriage status (or marriage happiness) and capacity in handling arguments. The estimates have no statistical significance in the simple model and endogeneity models, and the null hypothesis of exogenous choice of college education cannot be rejected by the endogeneity test. These results indicate that a college education does not increase the individual's capacity to communicate effectively and to socialize with others.

\section{References}

Alesina, A. \& La Ferrara, E. (2000) The determinants of trust. NBER working paper 7621.

Alesina, A., \& La Ferrara, E. (2002). Who trusts others? Journal of Public Economics, 85(2), 207-234.

Barber, A. (1983). The logic and limits of trust. New Brunswick, NJ: Rutgers University Press.

Bhattacharya, J., Goldman, D., \& McCaffrey, D. (2006). Estimating probit models with self-selected treatments. Statistics in Medicine, 25(3), 389-413.

Bjørnskov, C. (2007). Determinants of generalized trust: A cross-country comparison. Public Choice, 130(1), 1-21.

Bluhm, L. (1987). Trust, terrorism and technology. Journal of Business Ethics, 6, 333-341.

Blundell, R., Dearden, L., \& Sianesi, B. (2005). Evaluating the impact of education on earnings in the UK: Models, methods and results from the NCDS. Journal of the Royal Statistical Society Series A, 168(3), 473-512.

Boyle, R., \& Bonacich, P. (1970). The development of trust and mistrust in mixed-motive games. Sociometry, 33(2), 123-139.

Brehm, J., \& Rahn, W. (1997). Individual-level evidence for the causes and consequences of social capital. American Journal of Political Science, 41, 999-1023.

Brewer, M., \& Kramer, R. (1985). Intergroup relations. American Review of Psychology, 36, 219-243.

Buskens, V. (2002). Trust and social networks. Boston, MA: Kluwer.

Case, A., Fertig, A., \& Paxson, C. (2005). The lasting impact of childhood health and circumstance. Journal of Health Economics, 24(2), 365-389.

Coleman, J. (1988). Social capital in the creation of human capital. American Journal of Sociology, 94(Supplement), 95-120.

Coleman, J. (1990). Foundation of social theory. Cambridge, MA: Harvard University Press.

Delhey, J., \& Newton, K. (2005). Predicting cross-national levels of social trust: Global pattern or Nordic Exceptionalism? European Sociological Review, 21(4), 311-327.

Ferraro, K. (1995). Fear of crime. Albany, New York: State University Press of New York.

Fukuyama, F. (1995). Trust. New York: Free Press.

Gambetta, D. (1988). Can we trust trust? In D. Gambetta (Ed.), Trust: Making and breaking cooperative relations. Oxford: Basil Blackwell.

Glaeser, Edward L., Laibson, David., Scheinkman, Jose A., \& Scoutter Christine L. (1999) What is social capital, the determinants of trust and trustworthiness. NBER working paper 7216.

Granovetter, M. (1973). The strength of weak ties. American Journal of Sociology, 78(6), 1360-1380.

Hardin, R. (1996). Trustworthiness. Ethics, 107(1), 26-42.

Hardin, R. (1998). Trust in government. In V. Braithwaite \& M. Levi (Eds.), Trust and governance. New York: Russell Sage Foundation.

Hardin, R. (2003). Conceptions and explanations of trust. In K. Cook (Ed.), Trust in society. New York: Russell Sage Foundation.

Heckman, J., \& Navarro-Lozano, S. (2004). Using matching, instrumental variables and control functions to estimate economic choice models. Review of Economics and Statistics, 86(1), 30-57.

Helliwell, J., \& Putnam, R. (1999) Education and social capital. NBER working paper No.7121.

Huang, J., Maassen van den Brink, H., \& Groot, W. (2009). A meta analysis of the effect of education on social capital. Economics of Education Review, 28(4), 454-464. 
Knack, S., \& Keefer, P. (1997). Does social capital have an economic payoff? A cross-country investigation. Quarterly Journal of Economics, 112(4), 1251-1288.

Knack, S., \& Zak, P. (2002). Building trust: Public policy, interpersonal trust, and economic development. Supreme Court Economic Review, 10, 91-107.

Knight, J. (2003). Social norms and the rule of law: Fostering trust in a socially diverse society. In K. Cook (Ed.), Trust in society. New York: Russell Sage Foundation.

Kollock, P. (1994). The emergence of exchange structures: An experimental study of uncertainty, commitment, and trust. American Journal of Sociology, 100(2), 313-345.

Kramer, R. (2004). Collective Paranoia: Distrust between social groups. In R. Hardin (Ed.), Distrust. New York: Russell Sage Foundation.

La Porta, R., Lopez-de-Silane, F., Shleifer, A., \& Vishny, W. (1997). Trust in large organizations. American Economic Review, 87(2), 333-338.

Levi, M. (1998). A state of governance. In V. Braithwaite \& M. Levi (Eds.), Trust and governance. New York: Russell Sage Foundation.

Lewis, D., \& Weigert, A. (1985). Trust as a social reality. Social Forces, 63(4), 967-985.

Lukes, S. (1991). The rationality of norms. Archives Européennes de Sociologie, 32, 142-149.

Marshall, M., \& Stolle, D. (2004). Race and the city: Neighborhood context and the development of generalized trust. Political Behavior, 26(2), 125-154.

Misztal, B. (1996). Trust in modern society. Cambridge: Polity Press.

Newton, K. (2001). Social trust and political disaffection: Social capital and democracy. Paper prepared for EURESCO conference on social capital: Interdisciplinary perspectives. Exeter, UK.

North, D. (1990). Institutions, institutional change and economic performance. Cambridge: Cambridge University Press.

Offe, C. (1999). Trust and knowledge, rules and decisions: Exploring a difficult conceptual terrain. In M. Warren (Ed.), Democracy and trust. Cambridge: Cambridge University Press.

Paxton, P. (2007). Association memberships and generalized trust: A multilevel model across 31 countries. Social Forces, 86(1), 47-76.

Pearl, J. (2000) Causality: Models, Reasoning, and Inference. Cambridge University Press.

Putnam, R. (1993). Making democracy work: Civic traditions in modern Italy. Princeton, NJ: Princeton University Press.

Putnam, R. (2000). Bowling alone: The collapse and revival of American community. New York: Simon and Schuster.

Rahn, W., Yoon, K. S., \& Loflin, K. (2003). Geographies of trust. paper presented at the 58th annual meeting of the American Association for Public Opinion Research, Nashville, TN.

Rothstein, B., \& Stolle, D. (2002). How political institutions create and destroy social capital: An institiutionalised theory for social capital. Paper presented at the 98th Meeting of American Political Science Association, Boston, MA.

Stolle, D. (2002) Trusting Strangers-The Concept of Generalized Trust in Perspective. G. S. Schaal (Ed.), Österreichische Zeitschrift für Politikwissenschaft, Schwerpunktheft 4, 397-412.

Sztompka, P. (1999). Trust: A sociological theory. Cambridge: Cambridge University Press.

Uslaner, E. (2002). The moral foundations of trust. Cambridge: Cambridge University Press.

Warren, M. (1999). Democracy and trust. Cambridge: Cambridge University.

Welch, M., Rivera, R., Conway, B., Yonkoski, J., Lupton, P., \& Giancola, R. (2005). Determinants and consequences of social trust. Sociological Inquiry, 75(4):453-473.

Yamagish, T. (2003). Trust as a form of social intelligence. In K. Cook (Ed.), Trust in society. New York: Russell Sage Foundation.

Yamagishi, T., \& Yamagishi, M. (1994). Trust and commitment in the United States and Japan. Motivation and Emotion, 18(2), 129-166.

Zack, P., \& Knack, S. (2001). Trust and growth. Economic Journal, 111(1), 295-321. 